\title{
Registros imagéticos: a interpretação da informação sob o aspecto cognitivo
}

\author{
Records imagistics: the interpretation of information under the cognitive aspect \\ Luiz Carlos Flôres de Assumpção ${ }^{l}$ \\ (lcfasms@bol.com.br) \\ André Porto Ancona Lopez $z^{2}$ \\ (apalopez@gmail.com) \\ http://dx.doi.org/10.5216/cei.v16i2.28035
}

\begin{abstract}
Resumo
As imagens fazem parte de nosso cotidiano de lazer, pessoal e profissional. O objetivo deste estudo é uma tentativa de entendimento do processo de interpretação e descrição das informações em registros imagéticos sob os aspectos cognitivos. A pesquisa bibliográfica foi realizada nas áreas da psicologia, filosofia e artes. E, conforme demonstração das análises das imagens neste estudo, ficou evidente que um indivíduo necessita de conhecimento sociocultural para, assim, ter condições de interpretação e descrição de imagens, além de conhecimento prévio acerca do contexto a ser analisado para estruturação de acervos imagéticos.
\end{abstract}

Palavras-chave: Registro Imagético. Informação. Interptretação. Descrição. Cognição.

\begin{abstract}
The images are part of our everyday leisure, personal and professional. This study is an attempt to understand the process of interpretation and description of imagistic information in records under the cognitive aspects. The literature search was performed in the areas of psychology, philosophy and the arts. And as demonstration of the analysis of images in this study it was clear that an individual needs sociocultural knowledge and thus, be able to interpret and image description, and previous knowledge about the context being examined for structuring imagistic collections.
\end{abstract}

Keywords: Record Imaging. Information. Interpretation. Description. Cognition.

\section{Introdução}

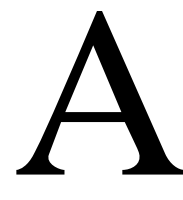

todo instante o ser humano depara-se com informações imagéticas, apresentadas em cartazes e anúncios, por histórias em quadrinhos e ilustrações de revistas, imagens nas páginas da internet, na televisão, no cinema, nas embalagens, nos objetos eletrônicos de consumo e comunicação. Ou seja, a realidade atual compõe-se de imagens e objetos. Este estudo tem relevância significativa para interpretação e descrição informacional de registros imagéticos em coleções, arquivos analógicos e on-line com a possibilidade de acesso, utilização e

\footnotetext{
${ }^{1}$ Doutorando em Ciência da Informação pela Universidade de Brasília (UNB). Mestre em Liderança pela Universidade de Santo Amaro (UNISA). Mestre em Ciência da Informação pela Universidade de Brasília (UNB).

${ }^{2}$ Professor da Faculdade de Ciência da Informação da Universidade de Brasília (UNB). Mestre e Doutor em História Social pela Universidade de Sçai Paulo (USP).
}

Comun \& Inf, v. 16, n. 2, p. 87-106, jul./dez. 2013 
recuperação da informação no contexto da ciência da informação, pois as representações das informações, das imagens e dos objetos são feitas, em geral, por um tipo de linguagem, podendo ser escrita (sinais e símbolos), falada ou através da imagem pictórica/fotográfica. No entanto, quando estas fazem parte do contexto arquivístico, não trazem a informação do antes ou do que se refere a imagem. Diante disso, surgiu o questionamento: Como podemos fazemos a interpretação da imagem? O objetivo deste estudo foi buscar o entendimento sobre a interpretação da informação imagética pictórica/fotografia sob o aspecto da cognição e da linguagem. Assim, limitamo-nos à interpretação da imagem sob os aspectos cognitivos e não em outras linhas de conhecimento, como a psicanálise e programação neurolinguística (PNL), que abordam diferentes aspectos da cognição e da informação.

Esta pesquisa refere-se à revisão bibliográfica onde foi possível perceber que o assunto é tratado pelos aspectos da psicologia, da filosofia e da arte, perpassando outras áreas do conhecimento que não são objeto desta pesquisa.

Podemos inferir que, para interpretação da imagem, dependemos da formação, do contexto e da bagagem cultural, conforme o período de convivência em determinado meio cultural e de que forma ocorreu a educação do indivíduo.

$\mathrm{Na}$ tentativa de responder à pergunta realizada anteriormente, faz-se necessário compreender como se processa determinada imagem, e se tal ação pode levar ao caminho da cognição, ou seja, da formação de pensamento do ser - aqui entendido como o ser humano - que processa e transcreve aquilo que vê. No caminho da cognição, é lícito percorrer uma linha histórica, tanto da Psicologia quanto da interpretação pictórica de Gombrich (2007, 2008), Berger (1999) e na iconologia e iconografia com Panofsky (2009), entre outros.

\section{Interpretação da Imagem}

"Os gregos diziam que se maravilhar é o primeiro passo no caminho da sabedoria e que, quando deixamos de nos maravilhar, estamos em perigo de deixar saber" (GOMBRICH, 2007, p. 7). Maravilhar-se, em virtude de poder conhecer, interpretar o que se vê, ou seja, tornar possível a descrição do que está à sua frente. "A maneira como vemos as coisas é afetada pelo que sabemos ou pelo que acreditamos. Só vemos aquilo que olhamos. O olhar é um ato de escolha." (BERGER, 
1999, p. 10). Ao buscar entender a formação da interpretação da imagem ${ }^{3}$ pelo homem, nos deparamos com uma análise de Campos (1990), que se refere ao trabalho de Panofsky sobre o espaço, o olhar e a linguagem. Vemos algumas pistas quando D'Amaral (1990) nos esclarece que "toda história do Ocidente pode ser contada como a história das alterações sintáticas que as relações entre o olho, o espaço e a linguagem foram sofrendo da Grécia clássica (ao menos - mas já basta) para cá" (D’AMARAL, 1990, p. 16). O que vemos nesta colocação é, justamente, quanto nossa forma de descrever o passado tem sido alterada pelo que se vê em relação à distância do objeto aqui tido como imagem - pode ser afetada pela distância da qual nos encontramos em relação a este objeto, ainda, o que contamos, ou seja, a linguagem que utilizamos para fazer a descrição do objeto. Nesse sentido, o mesmo autor nos apresenta uma tentativa de esclarecimento dessa linha:

[...] é todo um universo semântico extremamente importante para o que vieram a ser a filosofia, a ciência e a arte - derivado de verbos todos designativos de ver, que expressam a atitude de estar adiante, tomar distância, perceber, reter e contar. $\mathrm{O}$ espaço em que algo se apresenta ao olho que percebe sua presença, a linguagem (o discurso) que apresenta o percebido - eis uma estrutura, que convém chamar sintática, definidora da atitude ocidental. Nela é que algo como uma perspectiva pode vir a ganhar um sentido semântico, um valor de verdade. (D’AMARAL, 1990, p. 17).

Na visão deste autor, as formas de realizarmos a interpretação da imagem se dão pelo uso da linguagem, falada e escrita (uso de signos). A forma que "os metafísicos encontraram de superar os embaraços opostos pelos sofistas à estrutura grega de relação espaço-olho-imagem, foi construir uma espécie de proeminência desta última, redefinindo dessa forma as relações sintáticas da própria verdade" (D’AMARAL, 1990, p. 17). Essa dita verdade, então, seria a tentativa de se fazer entender a imagem representada pela linguagem. ““A partir de agora a linguagem representa’ vale menos a evidência do que se dá (espaço) do que o enunciado que conserva e retém (linguagem)" (D’AMARAL, 1990, p. 18). O autor contempla a visão na formação da verdade expressa daquilo

\footnotetext{
${ }^{3}$ Imagem (lat. imago, de imtari: imitar) Representação mental que retrata um objeto externo percebido pelos sentidos. "O termo ‘imagem' designa [...]certa maneira de a consciência se dar um objeto” (SARTRE, apud JAPIASSU, 2001, p. 101). Há várias controvérsias filosóficas quanto ao papel da imagem na constituição de nosso conhecimento do real, defendido especialmente pelos empiristas. Para alguns filósofos, a ideia é uma imagem mental do objeto externo, isto é, um retrato ou figuração deste que aparece em nossa mente. Outros objetam que nesse caso não seria possível termos imagens de objetos abstratos como a virtude, o triângulo (tomado em geral, e não um triângulo de tipo específico), etc., sendo que por esse motivo a representação não deve ser tomada como imagem. Entre os psicólogos, o termo "imagem" designa toda representação sensível (auditiva, tátil, etc.). Assim, podemos ter uma imagem de uma melodia em nossa cabeça, ou a imagem de nosso corpo. Essa imagem (objeto do espírito) se distingue desse outro objeto do espírito que é a ideia, na medida em que possui como ponto de partida uma percepção sensorial. A faculdade de produzir imagens mentais constitui a imaginação (JAPIASSU, 2001, p. 101).
}

Comun \& Inf, v. 16, n. 2, p. 87-106, jul./dez. 2013 
que vemos e interpretamos de um objeto, no qual passa a ser uma imagem refletida em nossa cognição e externalizada pela linguagem falada ou escrita, na representação oral, num texto, desenho ou gravura. Quando falamos de imagem refletida em nossa cognição, estamos tratando a forma que o homem faz para interpretar essa imagem, e a demonstração disso está em Gombrich (2007; 2008). Para fazermos uma análise sobre a interpretação da imagem pictórica, “[...] devemos aprender primeiro a conhecer os seus métodos de desenho para compreender-lhe os sentimentos. Depois de adquirirmos o entendimento dessas diferentes linguagens, poderemos até preferir obras de arte com expressões menos óbvias [...]" (GOMBRICH, 2008, p. 23). Ainda, “[...] somos todos propensos ao precipitado veredicto de que as coisas não se parecem com isso. Temos o curioso hábito de pensar que a natureza deve parecer-se sempre com as imagens que nos acostumamos" (GOMBRICH, 2008, p. 27).

O que Gombrich (2008) retrata, é a necessidade de o homem sempre buscar representar a natureza com imagens desde o aurignaciano ao século XX. "Do abstrato discutido no pré-chelense em diante nascem as culturas e vicejam as sementes de tudo que possuímos, desde o apito de osso até desintegração atômica [...].” (CASCUDO, 1973, p. 55). Esclarece, ainda, que:

[...] a relação das Idades, e nestas os Períodos, destina-se a fixar o aparecimento tipológico das utilidades que vieram aos nossos dias e fazem parte, com as modificações lógicas, de nossas exigências habituais ou conhecimentos comuns,

dentro da civilização em que vivemos. (CASCUDO, 1973, p. 55).

No entendimento de Gombrich (2008), no aurinhacense os caçadores acreditavam nas suas representações, ou seja, nas suas expectativas e crenças internas provocadas pela visão pictórica quando desenhavam nas cavernas. Contudo, Gombrich (2007, p. xv) comenta que "nunca houve imagem que fosse igual à natureza; todas as imagens baseiam-se em convenções, tal como a linguagem ou as letras do alfabeto". Porém, a linguagem não tem início direto da fala - emissão sonora, pois "como começou o Homem a falar é um mistério como todos os começos" (CASCUDO, 1973, p. 358). Muito dos aspectos e objetos vistos numa imagem trará consigo a influência da nossa própria expectativa e da linguagem ao tentarmos descrevê-la, nenhum instrumento de expressão artística poderia funcionar se não influenciasse tanto a nossa percepção através das expectativas criadas. Quem já tentou retratar um amigo ou se postou diante de um

Comun \& Inf, v. 16, n. 2, p. 87-106, jul./dez. 2013 
objeto para reproduzi-lo fielmente no papel ou na tela terá vivenciado as questões psicológicas tratadas aqui.

Essas questões psicológicas podem tanto influenciar a criação ou descrição funcionando como filtro. Para Gombrich (2007, p. xviii), “[...] sem esse filtro, seríamos soterrados pela miríade de estímulos que nos chega do mundo exterior. [...] e que a diferença entre sinais e imagens está no contexto mental diferente que temos de adotar para compreendê-los". Contudo, se observamos (na imagem ou um objeto, na leitura de um texto, etc.) ao fazermos a reinterpretação estaremos utilizando a linguagem e os signos símbolos ou imagens (grifo nosso) para isso, temos de ter experimentado ou tido algum tipo de experiência para podermos compreender. Com relação a isso, Gombrich (2007, p. 11) nos esclarece que:

[...] nada é visto, mesmo no espetáculo que temos diante dos olhos, se não tiver sido, de alguma maneira, conhecido e buscado previamente em outro contexto; e inúmeras diferenças observáveis entre as idades da ignorância e do conhecimento mostram o quanto a contração ou extensão da nossa esfera da visão depende de outras considerações que não simples retorno à óptica natural.

Porém, é difícil nos desembaraçarmos da interpretação - análise interior - do que realmente vemos do que apenas sabemos. Para entendimento do exposto, o autor nos apresenta um exemplo de como é a percepção pela visão e noção de espaço: "Uma esfera parece ao olho um disco chato; é o tato que nos ensina as propriedades de espaço e forma" (GOMBRICH, 2007, p. 13). E, por consequência, "o desenvolvimento dos sentidos em qualquer organismo começa com a sensação, com o tato" (GOMBRICH, 2007, p. 16). No entanto, há correntes de estudos apontando para uma vertente em que o conhecimento passa a ser formado a partir de um contexto de convivência social conforme apresentados por Vigotsky (2011a; 2011b). Ou seja, em todas as áreas do conhecimento sempre há correntes que se aprofundam em um determinado ponto e outros seguem caminhos contrários. Isso não quer dizer que um estudo invalida o outro, pois, de acordo com Kuhn (2009), são abordagens de um mesmo objeto com paradigmas diferentes. Vigotsky (2011a) defende que o conhecimento se dá através da interação social entre o sujeito e outros sujeitos juntamente com os objetos em seu meio através das interrelações construídas na convivência, ou seja, o amadurecimento psicológico e sociocultural do indivíduo. Conforme entendemos, os desenvolvimentos dos processos psicológicos superiores passam a ser definidos com o uso de instrumentos - no caso a mão. Vigotsky (2011a) também questiona o posicionamento dos estudos 
do desenvolvimento das crianças ao caráter botânico onde se associava à maturação do organismo como um todo.

O fato, no entanto, é que a maturação per se é um fator secundário do desenvolvimento das formas típicas e mais complexas, do comportamento humano. [...]. A noção corrente de maturação como um processo passivo não pode descrever, de forma adequada, os fenômenos complexos. (VIGOTSKY, 2011a, p. 4).

Contudo, para Vigotsky (2011a) essas linhas de estudos da psicologia, quando tratada com base na analogia botânica, não seriam suficientes para poder dar conta da descrição do desenvolvimento infantil. $\mathrm{O}$ seus estudos passam a analisar as bases das pesquisas adotadas pela comparação do comportamento das crianças com os animais.

A resposta a essa crítica à psicologia moderna subiu um degrau na explicação científica, adotando modelos zoológicos como base de uma nova abordagem geral na compreensão do desenvolvimento infantil. [...]. As observações em que esses modelos se baseiam provêm quase que inteiramente do reino animal, e as tentativas de respostas para as questões sobre as crianças são procuradas na experimentação animal. (VIGOTSKY, 2011 a, p. 4).

De acordo com Vigotsky (2011a), os estudos passaram a fazer parte de um contexto mais amplo, saindo dos laboratórios de psicologia e indo para a prática do dia a dia. Onde "os resultados destas experimentações como os próprios procedimentos para obtê-lo estão sendo transposto dos laboratórios de experimentação animal para as creches" (VIGOTSKY, 2011a, p. 4). Deste modo, os resultados destas pesquisas acabaram direcionando para o estudo da inteligência prática para compreensão do uso dos instrumentos na percepção das coisas e a interação com outros humanos e os objetos.

Sendo que o raciocínio prático das crianças apresentam alguns pontos semelhantes como o pensamento adulto, diferindo em outros, além de enfatizarem o papel dominante da experiência social do desenvolvimento humano. [...], a experiência social exerce seu papel através do processo de imitação; quando a criança imita a forma pela qual o adulto usa instrumentos e manipula objetos, ela está dominando o verdadeiro princípio envolvido numa atividade particular. [...] que as ações, quando repetidas, acumulam-se uma sobre as outras, sobrepondo-se como numa fotografia de exposição múltipla; os traços comuns tornam-se nítidos, e as diferenças tornam-se borradas. (VIGOTSKY, 2011a, p. 8).

Para Vigotsky (2011a, p. 8), “a criança, à medida que se torna mais experiente, adquire um número cada vez maior de modelos que ela passa a compreender". Conforme o autor, "esses modelos representam um esquema cumulativo refinado de todas as ações similares, ao mesmo 
tempo em que constituem num plano preliminar para vários tipos possíveis de ação a se realizarem no futuro" (VIGOTSKY, 2011a, p. 8). Assim, podemos observar o que foi colocado por Gombrich (2007, 2008) e Panofsky (2009) sobre a necessidade do sujeito, ao fazer a interpretação de uma imagem, contar com uma bagagem cultural desenvolvida através das experiências conforme a percepção visual do que temos à nossa volta. A percepção visual tem importância no processo de interpretação e descrição, em que o pensamento conscientizado seria então o entendimento daquilo que se percebe, dos resultados das interações com o meio, com objetos e com outros seres humanos, formando estrutura cognitiva para interpretação dos acontecimentos em um determinado contexto de convívio sociocultural, econômico e ambiental. Assim, torna o indivíduo um ser pensante tendo a possibilidade de interpretar aquilo que percebe, vê ou sente. Podemos afirmar que a percepção visual tem importância no processo de interpretação e descrição informacional, e Forgus (1971), um dos que estudam o processo de informação em relação à percepção, declara ser um processo de extrair informação sobre o comportamento adaptativo.

Como o indivíduo obtém conhecimento sobre o ambiente é de importância primordial. Para se obter tal conhecimento é necessário extrair informação da vasta ordem de energia física, que estimula os sentidos do organismo. Somente aqueles estímulos que possuem valor de indício, isto é, que provam algum tipo de ação reativa ou adaptativa no indivíduo, deve ser logicamente chamado de informação. (FORGUS, 1971, p. 1).

De acordo com Forgus (1971), a aprendizagem pode ser definida como o processo pelo qual esta informação é adquirida através da experiência e se torna parte do armazenamento de fatos do organismo. Assim, "[...] o resultado da aprendizagem facilita a nova extração da informação, uma vez que os fatos armazenados se tornam modelos de acordo com os quais são julgados os indícios" (FORGUS, 1971, p. 3). E à “"[...] medida que o conjunto perceptivo vai sendo ampliado, tornando-se mais complexo e rico de padrões, através da experiência, mais capaz se torna o indivíduo de extrair informação do ambiente" (FORGUS, 1971, p. 3). Ou seja, na convivência o indivíduo internaliza a informação de um determinado contexto gerando mudanças. Ainda, “[...] nós consideramos a aprendizagem e o pensamento como eventos ou processos que auxiliam a extração da informação" (FORGUS, 1971, p. 3).

[...] a percepção como um processo contínuo que varia desde os eventos que são de natureza simples, elementar (e imediatamente ocorrem devido a um mecanismo de 
codificação montado) até aqueles de maior complexidade, que exigem aprendizagem e pensamentos mais ativos. (FORGUS, 1971, p. 5).

O autor nos apresenta uma descrição (Figura 1) sobre o funcionamento desse processo:

Neste o processo, os estímulos possuem a informação que é extraída pelo organismo sob a forma de aprendizagem. Esta aprendizagem modifica o organismo de modo que a percepção posterior dos mesmos estímulos será diferente. O processo de pensamento (resultante de aprendizagem prévia) também modifica o organismo porque ocorre nova aprendizagem; assim é que a percepção de estímulos sofre modificação. (FORGUS, 1971, p. 5).

Figura 1 - Relação entre aprendizagem e pensamento no complexo processo de percepção

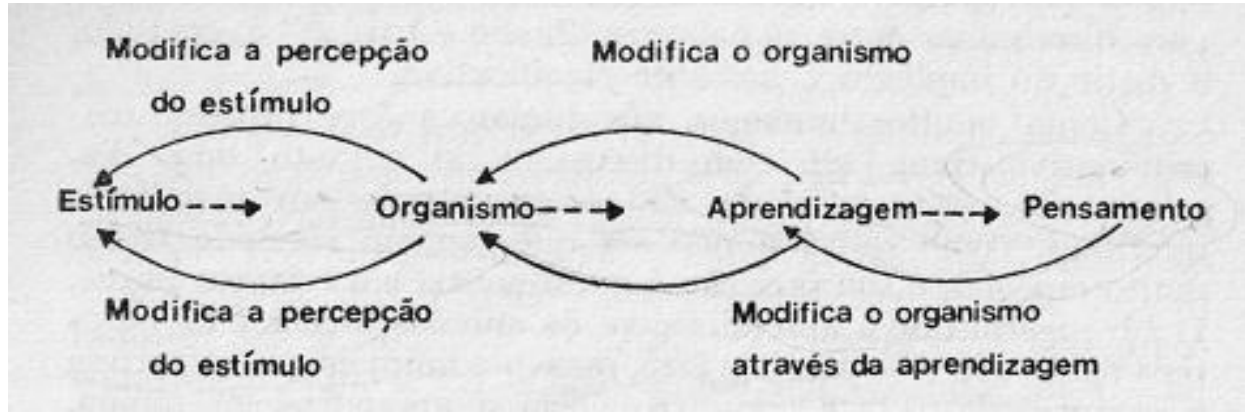

Fonte: Forgus (1971, p. 5)

Seu estudo está com consonância com os autores pesquisados (FRITZGERALD; STROMMEN, 1986; VIGOTSKY, 2011a, 2011b) quando afirma que: “[...] alguns perceptos são necessários antes de se tornar possível a aprendizagem, pois não podemos adquirir os fatos antes de tê-los primeiro percebido" (FORGUS, 1971, p. 5). Ao consideramos a influência do que já conhecemos para a interpretação e descrição da imagem de acordo com as abordagens expostas por Vigotsky (2011a e 2011b), Forgus (1971) e outros autores (FITZGERALD; STROMMEN, 1986; GOMBRICH, 2007; PANOFSKY, 2009), que abordam o desenvolvimento cognitivo e a descrição da imagem, é perceptível, no caso da interpretação de imagem pictórica/fotográfica por parte do ser humano, perpassar por uma bagagem de formação, ambientação, interrelações e mediação com o meio, também, pela educação visual ou ilusão daquilo que vemos.

Buscamos entender como a percepção ocorre e como percebermos alguns dos detalhes contidos nas imagens pictórica e/ou fotográfica. Kossoy (2007) nos faz um alerta de que há cerca de 60 anos, Pierre Francastel chamava a atenção para a importância das imagens enquanto meio de 
conhecimento. Observava também que "[...] Artes servem, pelo menos tanto quanto as Literaturas, como instrumento aos senhores das sociedades para divulgar e impor crenças" (KOSSOY, 2007, p. 30). Ou seja, há uma educação visual para entendimento da imagem percebida pelo sujeito observador.

\subsection{Educação visual ou ilusão}

A partir da interação e do desenvolvimento com o meio, somos apresentados a todos os tipos e estilos de imagens; assim começamos a aprender a identificar as coisas e objetos representados nelas, sendo essa visão compartilhada pelos autores pesquisados (GOMBRICH, 2007, 2008; VIGOTSKY 2011a, 2011b; FORGUS, 1971). No entanto, a percepção das imagens em perspectiva nos leva a crer em uma visão da realidade a qual não é verdadeira. Essa visão nos parece ser mais uma das formas pelas quais fomos educados a interpretar o que vemos numa fotografia ou num quadro em perspectiva. No entendimento de Neiva Jr. (1994), às vezes fazemos isso inconscientemente por achar que o que está sendo representado seja verdadeiro - mera ilusão - “[...] a perspectiva representa somente um dado da realidade: a maneira pela qual as linhas e os volumes se apresentam para o espectador" (NEIVA JR., 1994, p. 29). Complementa, que “[...] ela é, portanto, pura aparência, mera ilusão, que resulta na intenção consciente de enganar por parte de quem a desenha, pinta, esculpe ou planeja arquitetonicamente" (NEIVA JR., 1994, p. 29). Na Figura 2 buscamos entender como vemos uma imagem pelo lado da perspectiva.

Figura 2 - Alagamento na UNB, $2010^{4}$

\footnotetext{
${ }^{4}$ As fotografias utilizadas são meramente exemplos para a percepção em perspectiva e compreensão da diferença de percepção dos observadores quanto ao mesmo objeto de observação. As mesmas fazem parte de um acervo/coleção sem identificação descricional, cedido gentilmente pela Diretora do Centro de Documentação (CEDOC) da Universidade de Brasília (UnB), Tânia Maria de Moura Pereira, para fins didáticos, com seu uso nas aulas da disciplina Acervos Fotográficos, $2^{\circ}$ semestre de 2011.
}

Comun \& Inf, v. 16, n. 2, p. 87-106, jul./dez. 2013 


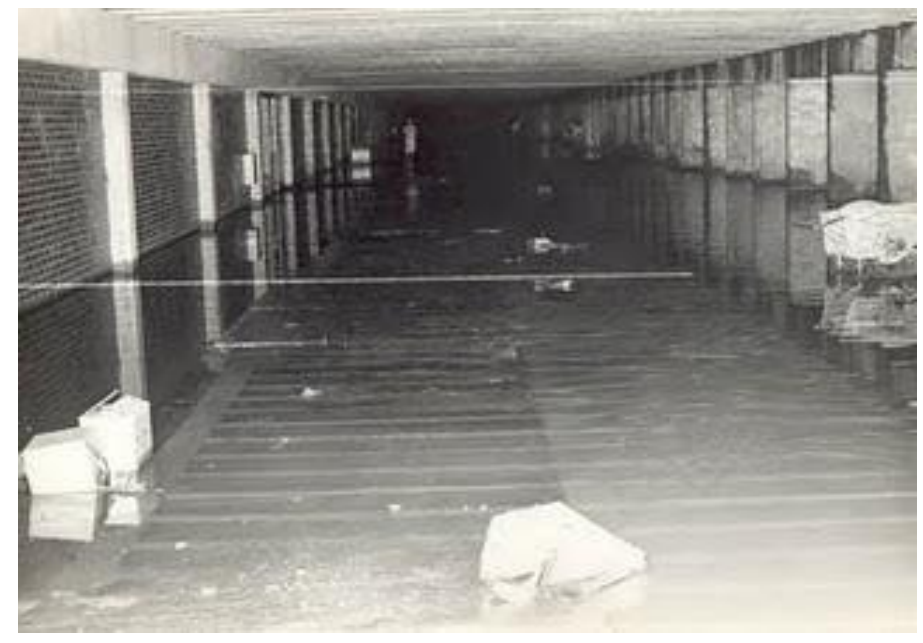

Fonte: CEDOC-UNB

Ao observarmos a fotografia acima, percebemos que a abertura do túnel na foto é maior que o final do túnel. Poderemos então, notar que isso não é real, já que as medidas e tamanho do túnel não são diferentes em sua extensão. Essa interpretação da imagem busca nos dar a noção de distanciamento. Então, “[...] a variação na ordem sensível da representação quer dizer que a perspectiva não é a transposição das condições supostamente eternas do olhar. As perspectivas são construções históricas” (NEIVA JR., 1994, p. 32-33). Temos a confirmação por Day (1974, p. 105), ao acentuar que "[...] a teoria funcionalista acentua igualmente o papel das hipóteses derivadas da experiência passada, hipóteses que se desenvolvem em consequência das transações do indivíduo e seu ambiente”. E na abordagem da percepção da psicologia (DAY, 1974, p. 106-107), “[...] a percepção pode ser considerada a partir de três categorias de variáveis: a do ambiente físico, a das interações e processos fisiológicos e a dos eventos comportamentais". Vejamos alguns exemplos:

Figura 3 - As janelas 


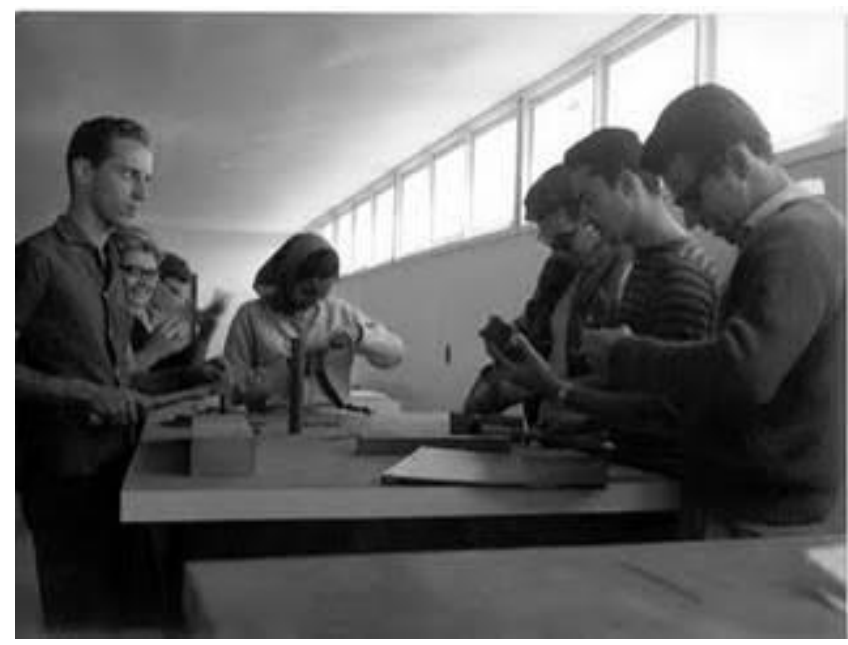

\section{Fonte: CEDOC-UNB}

Essa fotografia (Figura 3) nos demonstra outro exemplo de como o que a lente registra não é o que nosso olhar percebe. Mas, o que nossa mente interpreta em relação ao ambiente. Observemos as janelas.

Exemplo idêntico ao apresentado na fotografia anterior gera a percepção de profundidade, ficando nítido que “[...] perspectiva não representa a visão, mas é uma representação delas. Vemos da forma que não representamos, pois o olhar percebe de modo ligeiramente esférico, enquanto a perspectiva é linear" (NEIVA Jr., 1994, p. 33). Do exposto temos algumas indagações e esclarecimentos, vejamos: Por que, então, somos capazes de perceber uma pintura em perspectiva ou mesmo uma fotografia? Certamente porque fomos treinados para isso. No entendimento de Neiva Jr. (1994, p. 33), obras de arte como um todo, mesmo as em perspectiva, serão interpretadas, para isso haverá necessidade de se aprender a forma de leitura e/ou interpretação. O que ocorre é que nem sempre o espectador está em condições de fazer tal leitura. De acordo com Baxandall (1991), Gombrich (2007; 2008), Vigotsky (2011a, 2011b), Kossoy (2007), Berger (1999), Neiva Jr. (1994) e Panofsky (1995; 2009), é preciso haver bagagem cultural e técnica na leitura e interpretação de uma imagem para os registros imagéticos. Essa habilidade só é adquirida após a formação social e cultural do sujeito - experiências e educação.

\subsection{A descrição e a percepção sob a influência do olhar ou do que você é}


A influência do olhar... Será que o que descrevemos realmente é o que vemos? Se tratarmos essa pergunta sob o olhar de alguns pensadores da arte e, principalmente, sobre o registro imagético, poderemos ter o entendimento desta complexidade. No entanto, essa questão já fora tratada na visão da arte em si. Vamos perceber que essa complexidade não é de agora. Panofsky (2009) e Grombchi (2008), Campos (1990); Vigotsky (2011a, 2011b); Day (1974) e Forgus (1971) trazem esclarecimentos às questões tanto no campo da arte quanto da cognição.

Quando nos referimos à cognição, estamos falando da bagagem (conhecimento e experiências acumuladas) conforme visto anteriormente, que trazemos à tona ao fazermos a descrição do que vemos (interpretação da coisa que nos apresenta, podendo ser uma obra de arte, fotografia ou um objeto qualquer). Na fotografia, vemos a possibilidade de se captar tudo o que está sob o ângulo da lente, no entanto, esta captação está sob a influência de quem comanda a lente, quais intenções estão por trás da ação de apontar a lente. "Cada vez que olhamos uma fotografia estamos cientes, por mais superficialmente que seja, do fotógrafo selecionando aquela cena entre uma infinidade de outras possíveis" (BERGER, 1999, p. 12). Ao observarmos do ponto de vista do artista, temos a influência de quem está fazendo a representação (quadro ou fotografia) e de quem a encomendou. Na visão de Lopez (2000) e dos autores pesquisados (GOMBRICH, 2007, 2008; PANOFSKY, 1995, 2009; KOSSOY, 2007, 2009a, 2009b; BAXANDALL, 1991, BERGER, 1999), não difere do caso da fotografia que esteja num contexto institucional e administrativo. A captação e a representação desses dois contextos irão sofrer a influência do ambiente (aqui denominado de as condições em que se aponta uma lente ou de quando uma obra está sendo pintada). No caso da fotografia, para Berger (1999, p, 12), “[...] modo de ver do fotógrafo é reconstituído pelas marcas que ele faz na tela ou papel”. Nas obras de Gombrich $(2007,2008)$ fica evidente a necessidade de um conhecimento prévio para interpretação na arte, temos de descobrir prováveis intenções (inúmeras causas), finalidade da obra, o ambiente de criação, conhecer os métodos de desenho para compreender seus sentimentos. Ou seja, dessa forma, haverá a possibilidade de entender o que está exposto na imagem. Assim como a preocupação com o uso dos valores culturais de cada época reconstrução de um pedaço de evidência perdida - significado sociocultural naquele contexto em particular, principalmente se for de um registro imagético pictórico e/ou fotográfico pertencentes em uma coleção ou arquivo. E isso é demonstrado por Panofsky $(1995,2009)$ com uso da iconologia e iconografia. 


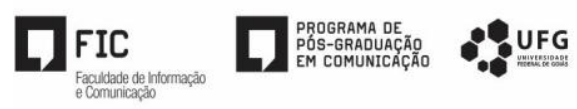

A título de exemplo, temos um garoto sendo pintado ou desenhado por um grupo, será igual à representação em todos os desenhos? De acordo com Panofsky (2009, p. 33), uma coisa é certa: "quanto mais a proporção de ênfase na ideia e forma se aproximam de um estado de equilíbrio, [...] mais a obra revelará o que se chama de 'conteúdo', ou cada vez mais se adaptará à intenção original das obras".

Figura 4 - O garoto

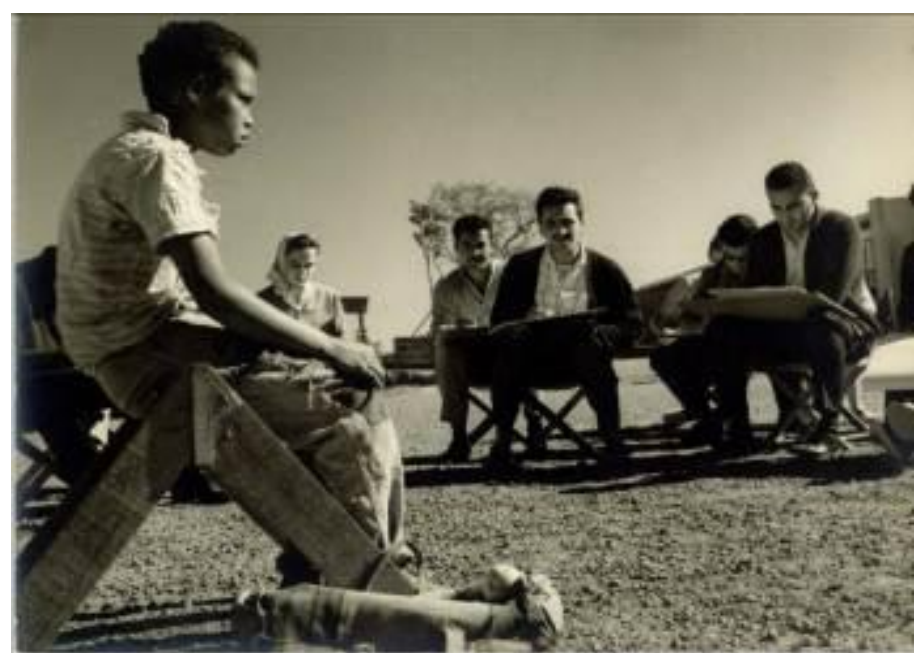

Fonte: CEDOC-UNB (2010)

No caso da fotografia acima (Figura 4), a reprodução do garoto sob o papel seria uma obra de arte? Qual a intenção e finalidade de se representar o garoto no papel? Se conhecermos os motivos, as finalidades e as causas, estaremos nos aproximando das intenções e assim de sua descrição, no entanto, isso não nos garante a fidedignidade do que realmente é.

Em outros termos, o mesmo objeto de observação retratado por determinado grupo poderá não ser igual em todos os detalhes, em sua descrição. Da mesma forma, se for de um contexto administrativo sem referência, nos levará a fazer qualquer descrição ou reutilização da imagem para outro propósito. Panofsky (2009), Gombrich (2008) e Kossoy (2007, 2009a, 2009b) concordam que isso vai depender da percepção ambiental e da bagagem que cada um destes elementos - sujeito "o observador" e o objeto "observado" - carregam consigo para uso posterior. Ou seja, ter uma fotografia e reutilizá-la em outro contexto diferente do que foi tirada (registrada - o clique) é bastante comum nos meios de comunicação. Outro exemplo é apresentado nas fotos a seguir (Figuras 5 e 6), nas quais temos uma pessoa vendo determinada área e fazendo um esboço do objeto 
observado. No entanto, temos outro observador dentre outros observadores que questionam a representação da visão do que está descrito ou desenhado.

Figura 5 - Observador

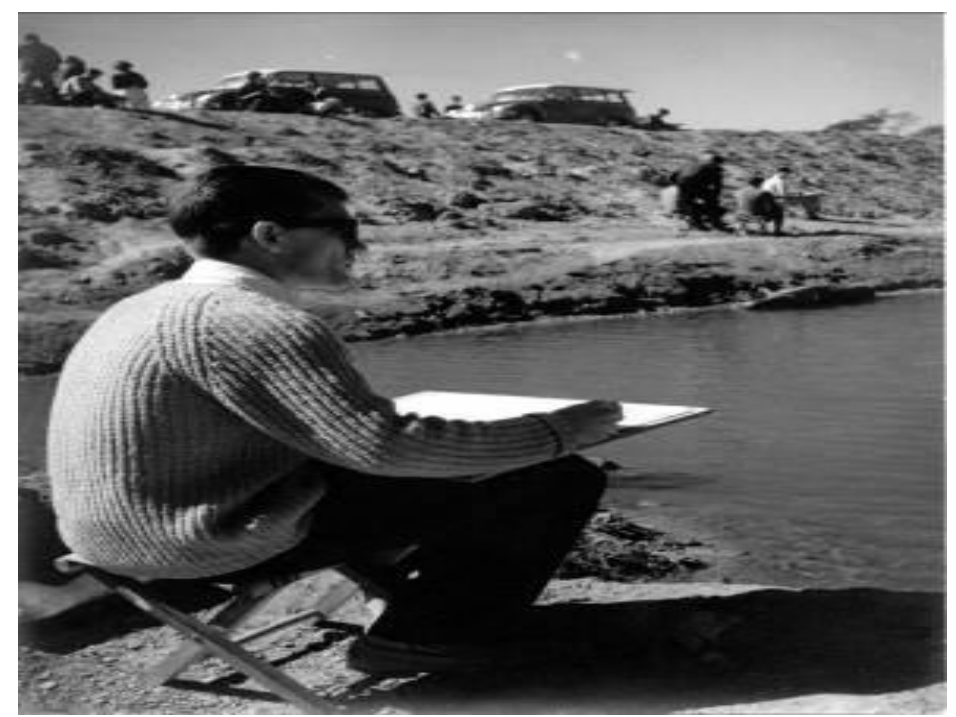

Fonte: CEDOC-UNB (2010)

Aqui, alguém (um indivíduo) está a contemplar uma paisagem ou objeto na qual irá fazer a sua descrição através da pintura, ou seja, neste momento o que será transposto para o papel é o que está se passando em seu processo de percepção e cognição para em seguida se tornar ação, o ato da pintura. Registro de um objeto/imagem percebido e reelaborado pelo processo cognitivo para transposição através da pintura no papel.

Figura 6 - Questionamento 


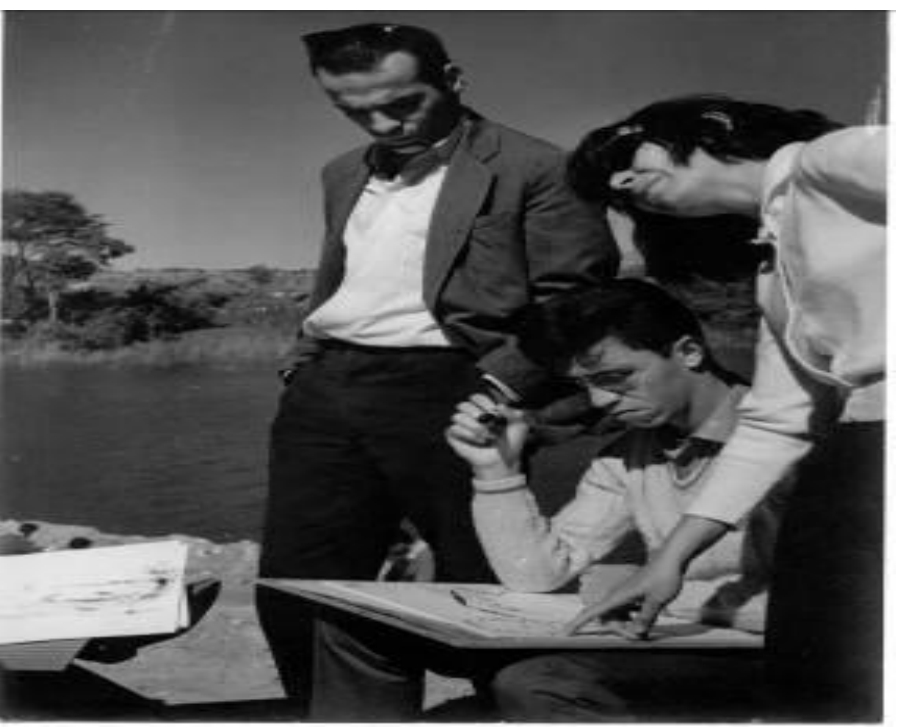

Fonte: CEDOC-UNB (2010)

No entanto, pode-se notar um questionamento por outros observadores, pois, o que um vê não é igual ao o que os outros veem. O nível de detalhamento e a forma como o objeto é retratado vai depender de cada sujeito que está no papel de observador. Panofsky (2009, p. 32) nos diz que "a intenção original não pode ser absolutamente determinada, é impossível definir as intenções com precisão científica". Ainda para esse autor, "a avaliação dessas intenções é mentalmente influenciada por nossa própria atitude, que, por sua vez, depende de nossas experiências individuais, bem como de nossa situação histórica" (PANOFSKY, 2009, p. 32-33).

Até agora tratamos da obra de arte e da fotografia como representação, no entanto, isso também se reflete nos arquivos. As obras de arte, quando dispostas no museu, têm suas características descritivas, mas não de acordo com Panofsky (2009), que afirma que vemos a obra em si e não a sua intencionalidade e demais aspectos, dando assim condições de se criar enorme quantidade de descrições. O entendimento sobre o antes da obra, de acordo com Baxandall (1991), seria quem encomenda e paga por ela, também definindo sua utilização, pois nesse período as melhores pinturas eram realizadas sob encomenda para um cliente, denominado mecenas, que pagava pela produção do artista e dos direitos em relação às obras, e também dava as especificações de como queria que fossem produzidas as obras. De acordo com Berger (1999, p. 24), este tipo de descrição só é encontrado em obras de alto valor econômico e histórico nos museus, quando há a necessidade de comprovação de sua origem/originalidade. O que ocorreu na produção das obras de 
arte não difere de hoje em relação às fotografias, por exemplo, o caso dos paparazzi ${ }^{5}$, quando buscam fotografar pessoas importantes que estejam em evidência na mídia. Uma determinada fotografia terá seu preço para as revistas ou tabloides - alguém paga pela fotografia - neste caso (gera um recibo - documento rastreável), apesar de não determinar o que deveria ser fotografado, escolhendo a que melhor convier em termos de impacto na mídia para então poder gerar um assunto e uma descrição do contexto.

No caso de uma fotografia de um evento institucional, é diferente. Teremos a intencionalidade e os motivos mais prementes, pois as fotografias irão fazer parte de um contexto documental, uma solicitação formal, determinando alguém ou algum fotógrafo para registrar o evento. No entanto, se olharmos um arquivo de uma instituição pública ou particular raramente encontraremos as pistas documental do antes. Com relação à obra de arte, Baxandall (1991, p. 17) afirma que "[...] há um tipo de documento legal onde estão registrados os elementos essenciais referentes à relação que dava origem a uma pintura, acordo escritos estabelecendo as principais obrigações contratuais de cada parte" (o pintor e o cliente - mecenas). Fazendo uma comparação com a fotografia institucional ou encomendada, o processo não difere da obra de arte, ou seja, as relações ainda hoje são as mesmas, alguém encomenda e faz as recomendações sobre qual será o momento importante ou de quem deve aparecer na fotografia.

Até aqui, descrevemos o que denominamos de antes - o motivo, registrar o evento. No entanto, Kossoy (2009, p. 37) apresenta todo um processo descricional, porém o antes ele o denomina de assunto, onde entra outros aspectos como o fotógrafo e a tecnologia. Quando tratamos de acervos fotográficos, aqui denominados de arquivos imagéticos, os procedimentos não são os mesmos.

Lopez faz algumas considerações importantes:

Os organizadores de acervos de documentos imagéticos tendem, muitas vezes, a valorizar os conteúdos informativos da imagem, ao invés de seu contexto de produção, isto é, os motivos pelos quais os documentos foram produzidos. Deste modo, tem-se buscado, tanto para os procedimentos do arranjo, como para a descrição documental, a inserção dos "conteúdos" de cada imagem em imensos bandos de dados, alimentados pela ilusão (quase

\footnotetext{
${ }^{5}$ Paparazzi |pàpàrátzi| (palavra italiana, plural de paparazzo, de Paparazzo, personagem do filme La Dolce Vita, de Fellini), s. m. pl. Designação dada aos fotógrafos que perseguem celebridades e figuras públicas para obterem imagens inéditas. Singular: paparazzo (Disponível em: <http://www.priberam.pt/dlpo/defaultaspx?pal=paparazzi>. Acesso em: 17 ago. 2011, às 10h32).
} 
cientificista) de que esta classificação detalhada é satisfatória para dar conta de todas (ou quase todas) as buscas possíveis. Assim, assume-se uma determinada interpretação da imagem como a única "leitura" correta, ou, ao menos, como a mais "objetiva". Capaz de sintetizar, de modo quase universal, as imagens em questão. Como exemplo, podemos citar o uso do método de unitermos os descritores recomendados por diversos manuais nacionais, os quais, aliás, encaram os arquivos fotográficos como uma categoria à parte dos demais arquivos, muitas vezes denominando-os de "arquivos especiais". (LOPEZ, 1999, p. 50).

Nas fotografias utilizadas nos exemplos anteriores, seríamos capazes de realizar a descrição de forma satisfatória, mesmo sabendo que elas fazem parte de um contexto institucional administrativo - UNB/CEDOC. Por pertencerem a um arquivo institucional, deveriam dar-nos condições para tal. Para Lopez (1999), esse procedimento seria um tanto difícil, já que faltam elementos que nos deem subsídios para tanto, principalmente se entendermos os pontos de vista elencados por Panofsky (2009), Gombrich (2007, 2008) e Baxandall (1991), onde faltam as informações do antes e os motivos - esses são passíveis de serem rastreados para oferecer subsídio à descrição. Contudo, para Berger (1999, p. 30), hoje há o uso da linguagem de imagens, e, segundo ele, o que importa agora é quem usa essa linguagem e com que objetivo.

\section{Considerações finais}

Diante dos vários tipos de imagens e informações imagéticas que nos são apresentados e da falta de informação quando fazem parte de um contexto arquivístico e de acordo com o exposto pelos autores pesquisados, poderemos então inferir que a interpretação imagética tem uma flexibilização que perpassa pelo desenvolvimento sociocultural do indivíduo para possibilidade de interpretação desde o seu motivo - o antes, da visão enquadrada pelo fotógrafo no instante do clique, podendo ser uma encomenda, uma ordem de serviço, um pedido - o registro, do seu processamento, na reutilização desta imagem posterior a produção, ou seja, ela é mutante, podendo assumir qualquer posição de acordo com a intencionalidade do usuário.

Então, o que tentamos entender até o momento foi como realizarmos a interpretação e a descrição das imagens que estão contidas em registro imagético, podendo ser uma obra de arte ou fotografia, e, de acordo com Baxandall, Panofsky, Gombrich, Neiva e Vigotsky, na visão psicológica/cognitiva, fazendo parte de um arquivo institucional ou não. Diante disso, o que podemos concluir é que a interpretação da imagem, para sua descrição, consiste dos seguintes aspectos: 
- somente interpretamos ou descrevemos algo já conhecido, caso contrário, fazemos associações para descrição;

- precisamos nos disponibilizar de toda uma bagagem de conhecimento sociocultural para interpretação de uma imagem;

- a forma de como essa imagem será vista é afetada pelo ambiente e suas peculiaridades;

- em que meio foi registrada - fotografia ação mecânica, ou um quadro manual, tela podendo ser uma imagem de objeto ou do imaginário;

- identificar qual técnica utilizada no registro pictórico/fotográfico;

- identificar qual o conhecimento do espectador em relação à imagem que está sendo observada - aqui, irá compor o reconhecimento as experiências passadas e a bagagem cultural;

- saber qual a linguagem utilizada para descrição da imagem, a utilização de signos, podendo ser um texto, desenho ou a fotografia;

- a representação da imagem em perspectiva, não é o que realmente vemos, é uma forma de interpretação, na qual fomos treinados para ver;

- uma imagem tem autonomia, podendo originar várias outras, estas outras se tornando independente da imagem de origem;

- o processo inicial da formação da percepção e inteligência inicia-se na infância, conforme descrito pelos autores da psicologia;

- esse processo de percepção pode fazer suas adaptações conforme o meio ou o que conforme os psicólogos chamam de esquemas.

Esses aspectos estão no contexto de interpretação e da descrição de uma imagem para o profissional de informação e em constituição de acervos. Vale ressaltar, que esses níveis de percepção e de interpretação são para descrição informacional da imagem, registro e recuperação da informação em registros imagéticos com apoio da iconologia e iconografia proposto por Panofsky (1995, 2009) e Lopez (1999, 2000). Além desses, há de se alinhar as normas arquivísticas para acervos documentais que obedecem a padrões nacionais e internacionais para acervos imagéticos.

Artigo submetido em 24/01/2014 e aceito em 29/01/2014.

\section{Referências}


BAXANDALL, M. O olhar renascente: pintura e a experiência social na Itália da Renascença. São Paulo: Paz e Terra, 1991.

BERGER, J. Modos de ver. Rio de Janeiro: Rocco, 1999.

CAMPOS, J. L. de. Do simbólico ao virtual: a representação do espaço em Panofsky e Francastel. São Paulo: Perspectiva; Rio de Janeiro: UERJ, 1990.

CASCUDO, L. C. Civilização e cultura. v. 1 e 2. Rio de Janeiro: José Olimpio; Brasília: Instituto Nacional do Livro, 1973.

CEDOC-UNB [Fotografias sem título] 2010. Figuras 2, 3, 4, 5 e 6 fotografias.

DAY, R. H. Psicologia da percepção. 2. ed. Rio de Janeiro: José Olimpio, 1974.

D’AMARAL, M. T. Perspectiva e história: como se fosse um prefácio. In: CAMPOS, J. L. Do simbólico ao virtual: a representação do espaço em Panofsky e Francastel. São Paulo: Perspectiva; Rio de Janeiro: UERJ, 1990.

DICIONÁRIO PRIBERAM DE LÍNGUA PORTUGUESA. Disponível em:

<http://www.priberam.pt/dlpo/default.aspx?pal=paparazzi>. Acesso em: 17 ago. 2011.

FORGUS, R. H. Percepção: o processo básico do desenvolvimento cognitivo. São Paulo: Heder; Brasília: UNB; São Paulo: USP, 1971.

FRITZGERALD, H. E.; ESTROMMEN, E. A. Psicologia do desenvolvimento: o bebê e a criança pequena. Rio de Janeiro: Campus, 1986.

GOMBRICH, E. H. Arte e ilusão: um estudo da psicologia da representação pictórica. 4. ed. São Paulo: WMF Martins Fontes, 2007.

GOMBRICH, E. H. História da arte. 16. ed. Rio de Janeiro: LTC, 2008.

JAPIASSU, H.; MARCONDES, D. Dicionário básico de filosofia. 3. ed. Rio de Janeiro: Zahar, 2001.

KOSSOY, B. Os tempos da fotografia: o efêmero e o perpétuo. 2. ed. São Paulo: Ateliê Editorial, 2007.

KOSSOY, B. Fotografia \& história. 3. ed. rev. amp. São Paulo: Ateliê Editorial, 2009a.

KOSSOY, B. Realidade e ficções na trama fotográfica. 4. ed. ver. amp. São Paulo: Ateliê Editorial, 2009b. 
LOPEZ, A. P. A. Documentos imagéticos de arquivo: uma tentativa de utilização de alguns conceitos de Panofsky. Sinopses, São Paulo, n. 31, p. 49-55, jun. 1999.

LOPEZ, A. P. A. As razões e os sentidos: finalidades da produção documental e interpretação de conteúdos na organização arquivística e documentos imagéticos. Tese de Doutorado do Programa de Pós-Graduação em História Social da Faculdade de Filosofia, Letras e Ciências Humanas da Universidade de São Paulo, 2000.

NEIVA JR., E. A imagem. 2. ed. São Paulo: Ática, 1994.

PANOFSKY, E. Estudos de iconologia: temas humanísticos na arte do renascimento. 2. ed. Lisboa: Editorial Estampa, 1995.

PANOFSKY, E. Significado nas artes visuais. 3. ed. São Paulo: Perspectiva, 2009.

VIGOTSKY, L. S. A formação social da mente: o desenvolvimento dos processos psicológicos superiores. 7. ed. São Paulo: Martins Fontes, 2007/2011.

VIGOTSKY, L. S. Pensamento e linguagem. 4. ed. São Paulo: Martins Fontes, 2008/2011. 